Article

\title{
Chemotaxonomic Study of Bostrychia spp. (Ceramiales, Rhodophyta) Based on Their Mycosporine-Like Amino Acid Content
}

\author{
Maria Orfanoudaki ${ }^{1}$, Anja Hartmann ${ }^{1, *}$, Mitsunobu Kamiya ${ }^{2}$, John West ${ }^{3}$ and \\ Markus Ganzera ${ }^{1}$ (D) \\ 1 Institute of Pharmacy, Pharmacognosy, University of Innsbruck, Innrain 80-82, Innsbruck 6020, Austria; \\ maria.orfanoudaki@uibk.ac.at (M.O.); markus.ganzera@uibk.ac.at (M.G.) \\ 2 Department of Ocean Sciences, School of Marine Resources and Environment, Tokyo University of Marine \\ Science and Technology, Japan 4-5-7 Konan, Minato-ku, Tokyo 108-8477, Japan; mkamiy0@kaiyodai.ac.jp \\ 3 School of BioSciences, University of Melbourne, Parkville, Victoria 3010, Australia; jwest@unimelb.edu.au \\ * Correspondence: anja.hartmann@uibk.ac.at; Tel.: +43-512-507-58430
}

Received: 17 June 2020; Accepted: 16 July 2020; Published: 17 July 2020

\begin{abstract}
This study presents a chemotaxonomic investigation of the genus Bostrychia through the quantitation of the major mycosporine-like amino acids (MAAs). The presence of some cryptic species had been suggested in the $B$. moritziana/B. radicans complex and MAA-profiling in respective samples revealed different chemotypes within this species complex. Another possibly polyphyletic species is Bostrychia simpliciuscula; previous molecular phylogenetic analyses showed four genetic lineages within this species, one of which was recently distinguished as a new species. Phytochemical profiling of those samples used for DNA analyses revealed four different chemotypes, corresponding to the above four lineages and it supports the re-circumscription of the other three B. simpliciuscula lineages. Therefore, mycosporine-like amino acids are considered as suitable chemotaxonomic markers for the reassessment of the classification of $B$. simpliciuscula. The determination of the MAA patterns in these algae was possible after developing and validating a suitable high-performance liquid chromatography-diode array detector (HPLC-DAD) method.
\end{abstract}

Keywords: Bostrychia spp.; Bostrychia simpliciuscula; classification; chemotaxonomic markers; mycosporine-like amino acids; method validation

\section{Introduction}

Species of the genus Bostrychia Montagne are a prominent part of the mangrove algal flora in tropical and warm temperate environments [1]. Forty-one species are accepted taxonomically at present [2]. In 1989 King and Puttock reviewed and revised the taxonomy of this genus [3] and subsequent works have provide better insights into the physiology, mating and biogeography of the genus, leading to the reclassification of many Bostrychia species [4]. However, many species are still considered as polyphyletic, warranting further research for the revision of their taxonomy.

B. simpliciuscula is one of the species for which multiple cryptic species are known. Zuccarello et al. showed in 2018 that this species consists of four lineages that do not form a clade, but the lineages are sister to species with different morphologies. The authors showed that by branched monosiphonous laterals and the rhizoid morphology in haptera, these four lineages can be separated into two groups that, however, were still not monophyletic. According to their results, B. simpliciuscula is confined to the tropics, whereas one of the lineages matched a previously described species (B. tenuissima) found in Australasia, another lineage with the previous name B. hamana-tokidae is found in Japan, and the last lineage occurring in central New South Wales is actually a new species, B. kingii [5]. 
The Bostrychia moritziana/B. radicans species complex is comprised of seven molecular lineages [6], which are not reproductively inter-compatible [7]. Morphologically B. moritziana has been primarily distinguished by abundant compound monosiphonous lateral branches, whereas $B$. radicans had mostly polysiphonous laterals [8]. Additionally, West et al. described in 2013 a morphologically distinct lineage within the Bostrychia moritziana/B. radicans species complex as a new species, named B. anomala [9].

In order to perform a chemotaxonomic study on the genus Bostrychia an HPLC-DAD method for the quantification of MAAs in respective extracts was necessary. In the last years, several analytical studies were carried out investigating the mycosporine-like amino acid content of red algae, mainly using high-performance liquid chromatography as the preferred technique [10,11]. Yet, in most cases the number of analytes was too low to serve for a chemotaxonomic study, and therefore a HPLC-DAD method for the simultaneous determination of the twelve most common MAAs in red algae was established and validated according to the International Conference on Harmonisation (ICH) guidelines based on the determination of specificity, linearity, precision, and accuracy. Finally, the method's applicability for the determination of MAAs in Bostrychia spp. was proven by showing the differentiation of species belonging to the B. simpliciuscula/B. kingii and B. moritziana/B. radicans complex.

\section{Results}

\subsection{Method Development}

\subsubsection{Sample Preparation}

Prior to sample analysis optimum extraction and homogenization conditions were determined in an effort to determine the simplest and fastest method which was both reproducible and accurate. Different extraction procedures (sonication, maceration) and solvents (methanol, and mixtures of it with different water content) were investigated. Sonication-supported extraction of the plant material was found to be most efficient and $100 \%$ water the only solvent that enabled exhaustive extraction of all relevant compounds. Maceration and sonication with mixtures of water and methanol resulted either in partial extraction of the analytes or prolonged extraction time till exhaustive extraction was achieved. The sonication with higher amounts of $100 \%$ water with parallel decrease of the extraction duration or sonication repetitions (twice instead of three times) was also inadequate in terms of exhaustive extraction. Higher extraction temperatures were not investigated in order to avoid decomposition of possibly heat-sensitive analytes. The use of liquid nitrogen and a micropestle showed to be necessary for the formation of homogenously powdered plant material which was required for reproducible measurements. The sole use of the mill was sometimes impossible due to the small quantity of the available samples and even for bigger samples it was rejected because the resulting samples were not adequately homogenously milled. The efficiency of the applied extraction procedure was confirmed as follows: after preparing a sample as described in Section 4.4, the plant material was extracted once more and the supernatant analysed by HPLC. As no quantifiable amounts of the marker compounds were found in this solution, efficiency of the applied extraction procedure is proven.

\subsubsection{HPLC-DAD}

A similar method for MAA analysis was already described in a previous work [12], however it was not validated. A further adaption of this method was necessary, because the addition of compound $\mathbf{6}$, a main component of some Bostrychia spp., resulted in an overlap with compound 5. To accomplish the simultaneous quantitation of all major compounds in the shortest separation time, required the careful assessment of all important parameters again. Similar stationary phases, different acidic modifiers, buffers and flow rates were tested as mobile phase, but this did not result in the separation of compounds $\mathbf{5}$ and $\mathbf{6}$ without a negative effect on the peak shape, selectivity and resolution of the other MAAs. 
However, temperature seemed to play an important role in the separation of $\mathbf{5}$ and $\mathbf{6}$ (the lower the temperature, the better the separation), and in combination with isocratic conditions for the first twenty minutes of the separation these modifications resulted in improved separations. Now, under optimized conditions the separation of all standards (compounds 1-12, Figures 1 and 2) could be achieved in $40 \mathrm{~min}$. Subsequently, all twelve compounds could be assigned in red algae and specifically in Bostrychia extracts by comparison of their retention times and UV-spectra. Assignment of compounds is as follows: shinorine (1), palythine (2), asterina-330 (3), porphyra-334 (4), aplysiapalythine A (5), palythine-threonine (6); mycosporine-glycine (7) mycosporine-alanine-glycine (8), aplysiapalythine B (9), mycosporine-methylamine-threonine (10), usujirene (11) and palythene (12). It has to be mentioned that compound $\mathbf{5}$ which was used as a standard for the method validation of this study was isolated before and structurally assigned by NMR but palythinol shows identical mass, retention time and UV spectra with it [13], therefore the assignment of compound 5 in the present study is only tentative.<smiles>COC1=C(NC(CO)C(=O)O)CC(O)(CO)CC1=NCC(=O)[O-]</smiles><smiles>COC1=C(N)CC(O)(CO)CC1=NCC(=O)[O-]</smiles><smiles>COC1=C(NCCO)C[C@](O)(CO)CC1=NCC(=O)[O-]</smiles><smiles>COC1=C(NC(C(=O)O)[C@H](C)O)C[C@](O)(CO)CC1=NCC(=O)[O-]</smiles><smiles>COC1=C(NCC(C)O)C[C@](O)(CO)CC1=NCC(=O)[O-]</smiles><smiles>COC1=C(N[C@H](C(=O)[O-])[C@@H](C)O)CC(O)(CO)CC1=N</smiles><smiles>COC1=C(O)CC(O)(CO)CC1=NCC(=O)[O-]</smiles><smiles>COC1=C(NC(C)C(=O)O)C[C@](O)(CO)CC1=NCC(=O)[O-]</smiles>

5

6<smiles>CN=C1C[C@](O)(CO)CC(NC(C(=O)[O-])[C@H](C)O)=C1OC</smiles>

10<smiles>C/C=C\NC1=C(OC)C(=NCC(=O)[O-])CC(O)(CO)C1</smiles>
11<smiles>C/C=C/NC1=C(OC)C(=NCC(=O)[O-])CC(O)(CO)C1</smiles>

12

Figure 1. The structures of compounds 1-12.

\subsection{Method Validation}

Suitability of the developed HPLC method for the quantitation of compounds 1-12 in red algae can be deduced from several analytical parameters determined during validation. Calibration curves were constructed for compounds 1, 4, 5, 8 and 10 by plotting the peak areas against standard compound concentrations, and by using a linear least square fit regression model. Calibration data presented in Table 1 indicates linearity of the method in the tested range with a determination coefficient $\left(\mathrm{R}^{2}\right)$ higher than 0.9988 in all cases. For compounds 2, 3, and 8 sufficient material was not available, therefore they were quantified according to the calibration data of the structurally most similar compound 5, whereas compound 6 was quantified according to the calibration data of compound 4. Compounds 7, 11 and 12 
were not quantified due to stability reasons although their presence is reported in Table 2, Tables S1 and S2. Limits of detection (LOD) and limits of quantification (LOQ) ranged from $0.002 \mu \mathrm{g} / \mathrm{mL}$ to $0.0189 \mu \mathrm{g} / \mathrm{mL}$ and from $0.006 \mu \mathrm{g} / \mathrm{mL}$ to $0.0571 \mu \mathrm{g} / \mathrm{mL}$, respectively (Table 1 ). Assay precision was assured by repeatedly extracting and analysing the $B$. arbuscula sample. Intraday precision was found to be lower than $3.94 \%$ and interday precision lower than $5.15 \%$ for all analytes (Table 1 ).

Table 1. Validation parameters of the HPLC method.

\begin{tabular}{|c|c|c|c|c|c|c|}
\hline \multicolumn{7}{|c|}{ Calibration Data } \\
\hline Substance & $\begin{array}{l}\text { Regression } \\
\text { Equation a }\end{array}$ & $\begin{array}{l}\text { Coefficient of } \\
\text { Determination }\end{array}$ & \multicolumn{2}{|c|}{ Linearity $^{b}(\mu \mathrm{g} / \mathrm{mL})$} & $\begin{array}{c}\text { LOD } \\
(\mu \mathrm{g} / \mathrm{mL})\end{array}$ & $\begin{array}{c}\text { LOQ } \\
(\mu \mathrm{g} / \mathrm{mL})\end{array}$ \\
\hline 1 & $y=69632 x+2.8305$ & $\mathrm{R}^{2}=0.9997$ & \multicolumn{2}{|c|}{$0.0153-7.8125$} & 0.0020 & 0.0060 \\
\hline 4 & $y=68147 x+2.6536$ & $\mathrm{R}^{2}=0.9998$ & \multicolumn{2}{|c|}{$0.0557-7.125$} & 0.0094 & 0.0284 \\
\hline 5 & $y=45708 x+4.9671$ & $\mathrm{R}^{2}=0.9988$ & \multicolumn{2}{|c|}{$0.0669-34.250$} & 0.0118 & 0.0359 \\
\hline 8 & $y=51522 x+2.3346$ & $\mathrm{R}^{2}=0.9999$ & \multicolumn{2}{|c|}{$0.0605-7.750$} & 0.0101 & 0.0306 \\
\hline 10 & $y=32772 x+4.1515$ & $\mathrm{R}^{2}=0.9998$ & \multicolumn{2}{|c|}{$0.1621-41.5$} & 0.0189 & 0.0571 \\
\hline \multicolumn{7}{|c|}{ Accuracy and Precision } \\
\hline \multicolumn{3}{|c|}{ Precision } & \multicolumn{4}{|c|}{ Accuracy ${ }^{e}$} \\
\hline Substance & Intra-day ${ }^{c}$ & Inter-day ${ }^{d}$ & Substance & Low & Medium & High \\
\hline 1 & 3.94 & 5.15 & 1 & $95.11 \pm 1.33$ & $92.70 \pm 0.66$ & $92.59 \pm 0.32$ \\
\hline 2 & 3.67 & 3.55 & 4 & $97.93 \pm 0.33$ & $97.04 \pm 0.56$ & $97.53 \pm 0.28$ \\
\hline 3 & 3.54 & 4.98 & 5 & $97.45 \pm 1.57$ & $95.78 \pm 0.24$ & $95.67 \pm 0.80$ \\
\hline 4 & 3.76 & 3.67 & 8 & $97.89 \pm 4.85$ & $95.08 \pm 0.64$ & $95.29 \pm 0.85$ \\
\hline 5 & 3.87 & 4.06 & 10 & $96.22 \pm 4.68$ & $95.53 \pm 1.79$ & $96.64 \pm 2.22$ \\
\hline
\end{tabular}

For the assurance of accuracy, five marker compounds were utilized for spiking experiments. Recovery rates of the mentioned analytes were assessed at three different concentration levels (low, medium and high) and ranged from $92.59 \%$ to $97.93 \%$ (Table 1 ).

\subsection{Sample Analysis}

Various samples of Bostrychia spp. were analysed with the developed HPLC-DAD method. Due to the number of samples investigated only a summary of the results is shown in the main manuscript (Table 2) and all detailed results can be found in the Supplementary Material (Tables S1 and S2). As can be seen in the aforementioned tables, only eight out of 12 reference compounds could be determined in these samples since none of the samples contained compounds 8-10 and 12. Compounds $\mathbf{1}$ and 4 were the most frequently occurring compounds, although compound $\mathbf{1}$ was mostly present in minor concentration (lower than $0.15 \mathrm{mg}$ per g of dry material). Compound 2 was only found in B. arbuscula and B. tenella samples, and compound $\mathbf{1 1}$ was only found in B. tenella samples. Compound $\mathbf{6}$ was the main MAA in B. flagellifera and samples of lineage 2 and 3 of B. calliptera, although this compound was often present in higher concentrations in the latter, which also contained compound 4 in lower amounts. B. flagellifera sometimes produced an unknown compound absorbing at $320 \mathrm{~nm}$ and eluting at $7.6 \mathrm{~min}$ in a small concentration, too. Samples of lineage 1 of the B. simpliciuscula/B. kingii complex and $B$. harveyi samples produced compounds 4 and 6 in medium (concentration between 0.15 and $1 \mathrm{mg}$ per $\mathrm{g}$ of dry material) to high concentration (higher than $1 \mathrm{mg}$ per $\mathrm{g}$ of dry material) and compound 1 in lower amount. Compound 3 was the main MAA only for lineage 3 of the B. simpliciuscula/B. kingii complex (Figure 2). Compound 5 was the only MAA found in B. vaga and the main MAA found in all samples of the B. moritziana/B. radicans complex (Figure 3). 
Table 2. Overview of the MAA pattern in the investigated Bostrychia spp., mean values expressed as mg per g of dry material and standard deviation is reported in parenthesis. (detailed results can be found in supplementary material, Tables S1 and S2), assignment of compounds: SHI, Shinorine (1); PAL, Palythine (2); AST, Asterina-330 (3); POR, Porphyra-334 (4); APA, Aplysiapalythine A (5); PT, Palythine-Threonine (6); MG, Mycosporine-Glycine (7) and US, Usujirene (11). Assignment of the species: B sim, B. simpliciuscula; B kin, B. kingii; B rad, B. radicans; B ano, B. anomala; B mor, B. moritziana; B arb, B. arbuscula; B int, B. intricata; B tan, B. tangatensis; B vag, B. vaga; B har, B. harveyi; B ten, B. tenella; B fla, B. flagellifera; B cal, B. calliptera; B rdco, B. radicosa.

\begin{tabular}{|c|c|c|c|c|c|c|c|c|c|c|c|c|c|}
\hline Sample & SHI (1) & PAL (2) & AST (3) & POR (4) & $\mathrm{APA}^{*}(5)$ & PT (6) & MG (7) & US (11) & $\begin{array}{l}\text { MAA at } \\
7.6 \mathrm{~min}\end{array}$ & $\begin{array}{l}\text { MAA at } \\
9.9 \mathrm{~min}\end{array}$ & $\begin{array}{l}\text { MAA at } \\
8.0 \mathrm{~min}\end{array}$ & $\begin{array}{l}\text { MAA at } \\
21.5 \mathrm{~min}\end{array}$ & $\begin{array}{l}\text { MAAs at } 5.1 \\
\text { and } 6.4 \mathrm{~min}\end{array}$ \\
\hline B cal 1 & & & & & & & & & & & & & Present \\
\hline $\mathrm{B}$ cal 2,3 & & & & $0.03( \pm 0.05)$ & & $0.44( \pm 0.41)$ & & & & & & & \\
\hline B fla & & & & & & $0.18( \pm 0.22)$ & & & $\begin{array}{l}\text { Sometimes } \\
\text { Present }\end{array}$ & & & & \\
\hline B har & 0.08 & & & 2.689 & & 0.731 & & & & & & & \\
\hline B ten & $0.03( \pm 0.12)$ & $0.01( \pm 0.08)$ & $0.01( \pm 0.08)$ & $0.46( \pm 0.46)$ & & $0.06( \pm 0.07)$ & $\begin{array}{c}\text { Sometimes } \\
\text { Present }\end{array}$ & $\begin{array}{c}\text { Sometimes } \\
\text { Present }\end{array}$ & Present & $\begin{array}{c}\text { Sometimes } \\
\text { Present }\end{array}$ & & & \\
\hline $\mathrm{B} \operatorname{sim} 1$ & $0.15( \pm 0.08)$ & & & $0.98( \pm 0.49)$ & & $0.55( \pm 0.29)$ & & & & & & & \\
\hline B sim 4 & $0.02( \pm 0.01)$ & & & $2.04( \pm 1.07)$ & & & & & & & & & \\
\hline B int & $0.07( \pm 0.08)$ & & & $1.04( \pm 0.26)$ & & & & & & & & & \\
\hline $\mathrm{B} \tan$ & $0.07( \pm 0.04)$ & & & $0.34( \pm 0.11)$ & & & & & & & & & \\
\hline B rdco & $0.15( \pm 0.21)$ & & & $0.08( \pm 0.02)$ & & & & & & & & & \\
\hline B arb & 0.01 & 0.54 & 0.05 & 2.11 & 0.74 & & & & & & & & \\
\hline B ano & & & $0.37( \pm 0.42)$ & $0.11( \pm 0.22)$ & $3.46( \pm 1.15)$ & & & & & & & & \\
\hline $\mathrm{B} \mathrm{rad} /$ mor 1 & & & & $0.03( \pm 0.04)$ & $2.22( \pm 0.88)$ & & & & & & & & \\
\hline B rad/mor 2 & $0.14( \pm 0.18)$ & & $0.19( \pm 0.14)$ & $3.80( \pm 2.34)$ & $4.00( \pm 1.49)$ & & & & & & & & \\
\hline $\mathrm{B} \mathrm{rad} /$ mor 5 & & & $0.004( \pm 0.01)$ & $0.08( \pm 0.15)$ & $2.44( \pm 1.35)$ & & Present & & & & & & \\
\hline B rad/mor 6 & & & $0.04( \pm 0.08)$ & $0.05( \pm 0.1)$ & $2.40( \pm 0.87)$ & & Present & & & & & & \\
\hline $\mathrm{B} \mathrm{rad} / \mathrm{mor} 7$ & & & $0.41( \pm 0.39)$ & & $3.84( \pm 0.46)$ & & & & & & & & \\
\hline B vag & & & & & 0.15 & & & & & & & & \\
\hline $\mathrm{B} \operatorname{sim} 3$ & $0.23( \pm 0.23)$ & & $3.45( \pm 2.95)$ & & $0.67( \pm 0.95)$ & & & & & & & & \\
\hline $\mathrm{B} \operatorname{kin}(\mathrm{B} \operatorname{sim} 2)$ & & & & & & & & & & & Present & Present & \\
\hline
\end{tabular}

* Tentative assignment because palythinol shows identical mass, retention time and UV spectra. 


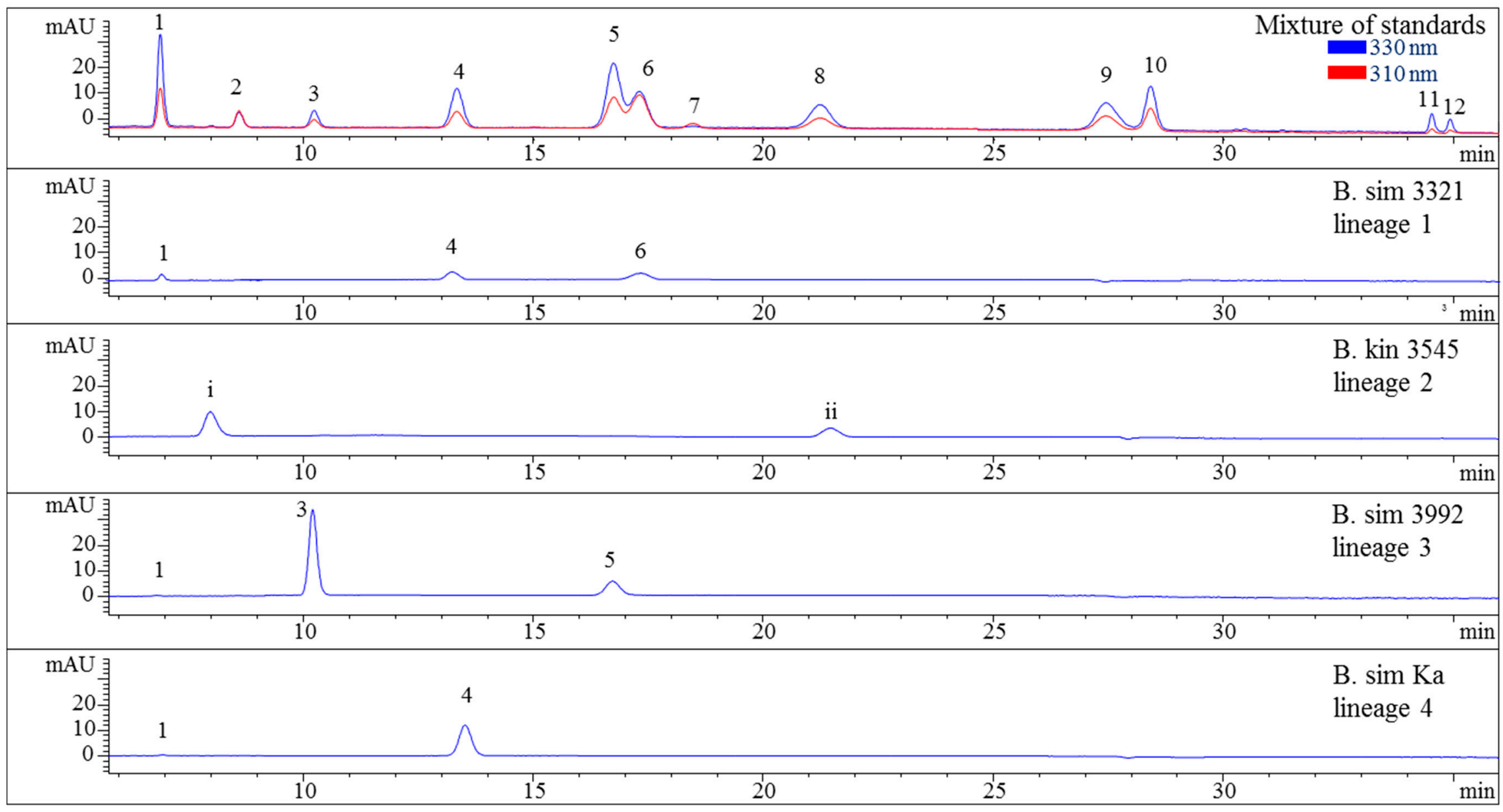

Figure 2. HPLC chromatograms of selected representatives of the four lineages of the B. simpliciuscula/B. kingii complex. Assignment of the compounds is according to Figure 1 and (i) unidentified MAA at 9.9 min with $\lambda \max 318 \mathrm{~nm}$ and $m / z$ 294, (ii) unidentified MAA at $21.5 \mathrm{~min}$ with $\lambda \max 308 \mathrm{~nm}$ and $m / z 316$. The assignment of 5 as Aplysiapalythine A is tentative. Assignment of the species: B sim, B. simpliciuscula; B kin, B. kingii. 


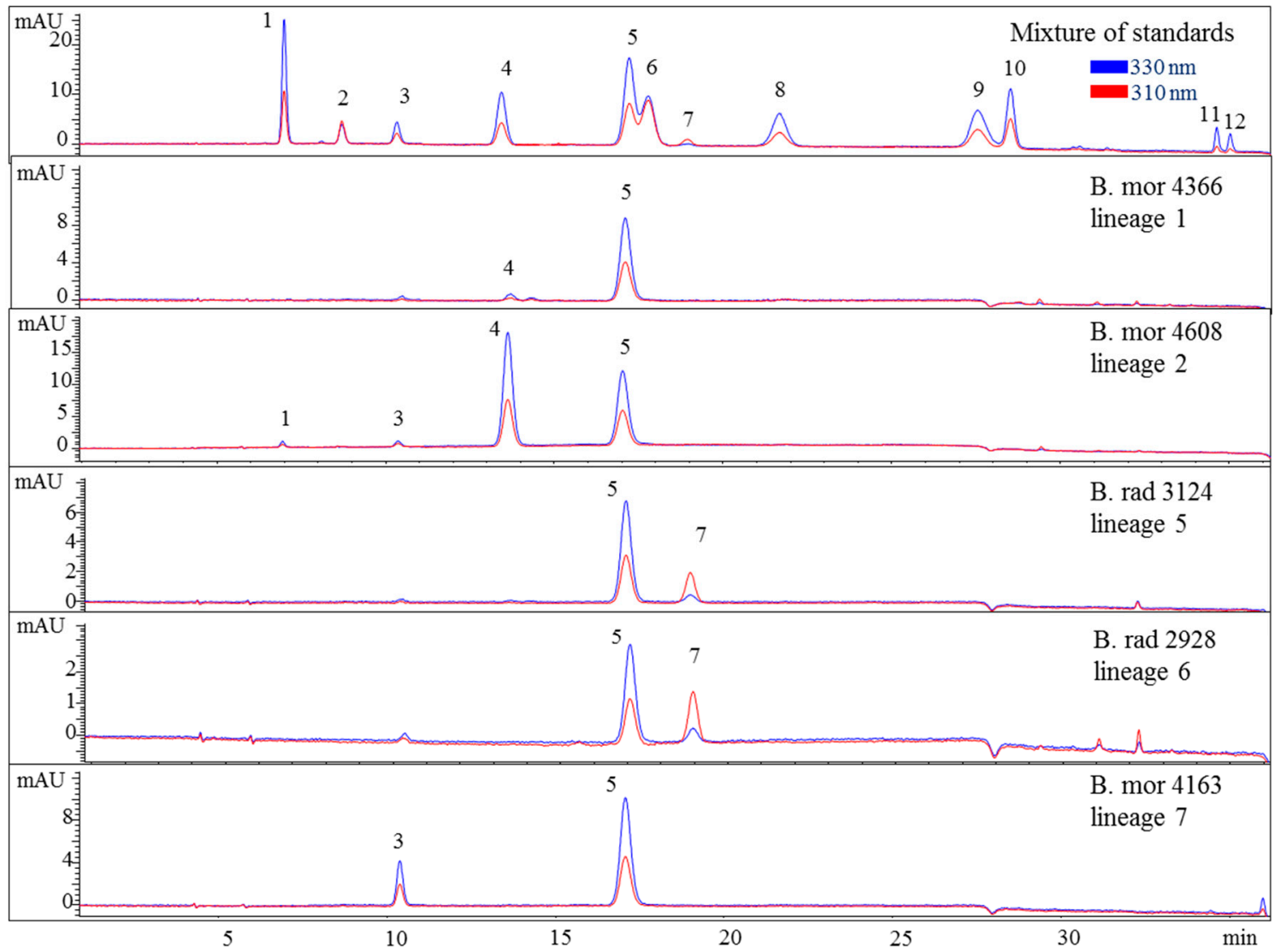

Figure 3. HPLC chromatograms of selected representatives of the lineages of the B. moritziana/ $B$. radicans complex. Assignment of the compounds is according to Figure 1 . The assignment of 5 as Aplysiapalythine A is tentative. Assignment of the species: B rad, B. radicans; B mor, B. moritziana.

Nevertheless, the additional presence of compound 4 enabled the differentiation of lineages 1 and 2 of the B. moritziana/B. radicans complex, respectively. On the other hand, samples of lineage 7 of the B. moritziana/B. radicans complex did not produce compound 4 but compound 3 instead. This pattern was similar to the MAA composition of $B$. anomala samples, although compound 3 was present in lower concentration. Furthermore, B. radicans samples (lineages 5 and 6 of the B. moritziana/ $B$. radicans complex) could be distinguished from the rest of the lineages in this complex due to the presence of compound 7. Compound 4 was the main MAA in B. tenella, B. intricata, lineage 4 of the B. simpliciuscula/B. kingii complex, B. tangatensis and B. arbuscula. In all of these species compound 1 was additionally present. $B$. arbuscula was the only species which produced compounds $1-5$, while B. tenella also produced compounds 6,7 and 11, in addition to two unknown MAAs at 7.6 and 9.9 min. B. intricata and lineage 4 of the B. simpliciuscula/B. kingii complex only showed two MAAs, compound 1 in low and 4 in high concentration. The same compounds were also present in B. tangatensis and B. radicosa samples, but compound 4 was found in medium concentration in the first species and low concentration in the second. Finally, lineage 2 of the B. simpliciuscula complex, recently accepted as B. kingii, produced two currently unknown, new MAAs at 8 and $21.5 \mathrm{~min}$, while lineage 1 of $B$. calliptera produced two unknown MAAs at 5.1 and $6.4 \mathrm{~min}$.

\subsection{LC-MS Based Analyte Identification}

As shown in Table 3, HPLC-DAD-MS experiments allowed the determination of the mass of additional, unknown compounds in Bostrychia extracts (Figures S1-S4); their UV spectra pointed to MAAs. Due to co-elution with a high amount of non-absorbing betaines, the mass of these MAAs in B. calliptera at 5.1 and 6.4 min could not be identified. 
Table 3. Absorption maxima and molecular mass of unidentified compounds, most likely MAAs, in the extracts of Bostrychia spp.

\begin{tabular}{ccc}
\hline Retention Time & $\lambda \max (\mathbf{n m})$ & Mass $(\mathbf{D a})$ \\
\hline 7.6 & 320 & 274 \\
\hline 8.0 & 334 & 403 \\
\hline 9.9 & 318 & 294 \\
\hline 21.5 & 308 & 316 \\
\hline
\end{tabular}

\section{Discussion}

In the present work, an HPLC-DAD method was modified and validated for the determination of the major MAAs in Bostrychia extracts in order to separate and quantify a high number of MAAs (12 compounds), which was necessary for the discrimination of Bostrychia species. Moreover, satisfactory validation results for all tested parameters, including sensitivity, linearity, precision, and accuracy, and suitability for the differentiation of Bostrychia spp. renders the developed analytical method in general useful for examining the MAA pattern of diverse red algae, not only for Bostrychia species. Prior to sample analysis optimum extraction and homogenization conditions were investigated and homogenously powdered plant material was acquired only after the use of liquid nitrogen and a micropestle. The addition of methanol at the extraction solvent, the reduction of the extraction time and repetitions were deterrent for the achievement of exhaustive extraction, thus three-times sonication with pure water for $15 \mathrm{~min}$ was selected.

The method's suitability to differentiate the four lineages of the B. simpliciuscula/B. kingii complex was also evaluated and confirmed. Zuccarello et al. showed in 2018 that this species consists of four lineages with specific geographic distribution, and one of them (B. kingii) was accepted as a new species. The authors also reported that lineage 1 matched a previously described species, $B$. tenuissima, while lineage 4 was identical to the previously described species B. hamana-tokidae. For lineage 3 they proposed to keep the currently accepted name, B. simpliciuscula. Their results based on sequencing data can be confirmed by the quantitative results summarized in Table 2 and Table S1, as well as by the Figures 2 and 4 . Therefore, our results also support the re-circumscription of the species. Each of the four lineages has a distinct MAA pattern; lineage 1 produces both porphyra-334 and palythine-threonine as the main MAAs, while lineage 4 shows only porphyra-334 as the main MAA. Asterina-330 is the dominant MAA in lineage 3, and two unknown MAAs are present in samples of lineage 2 (B. kingii).

Different chemotypes were also identified for samples belonging to the $B$. moritziana/B. radicans complex, in which seven lineages have been identified [6], and one of them was established as a new species, B. anomala [9]. In the present study, samples belonging to five out of the seven lineages were available, and in this case four chemotypes were identified corresponding to lineages 1, 2, 7 of this complex as well as 5 and 6 , which were indistinguishable. In all cases, they contained compound 5 in amounts higher than $1 \mathrm{mg}$ per g of dry material. Phytochemical investigations of these samples showed that although $B$. radicans samples belonging to lineages 5 and 6 were indistinguishable, they could be differentiated from lineages 1, 2 and 7 due to the production of mycosporine-glycine (Figures 3 and 5). B. moritziana samples of lineage 2 produced porphyra- 334 in amounts higher than $1 \mathrm{mg}$ per $\mathrm{g}$ of dry material, while for samples of lineage 1 the respective concentration was lower. B. moritziana samples of lineage $7 \mathrm{did}$ not produce porphyra-334 but instead a medium concentration of asterina- 330 could be measured. B. anomala samples contained asterina-300 as well, however in lower concentration. 


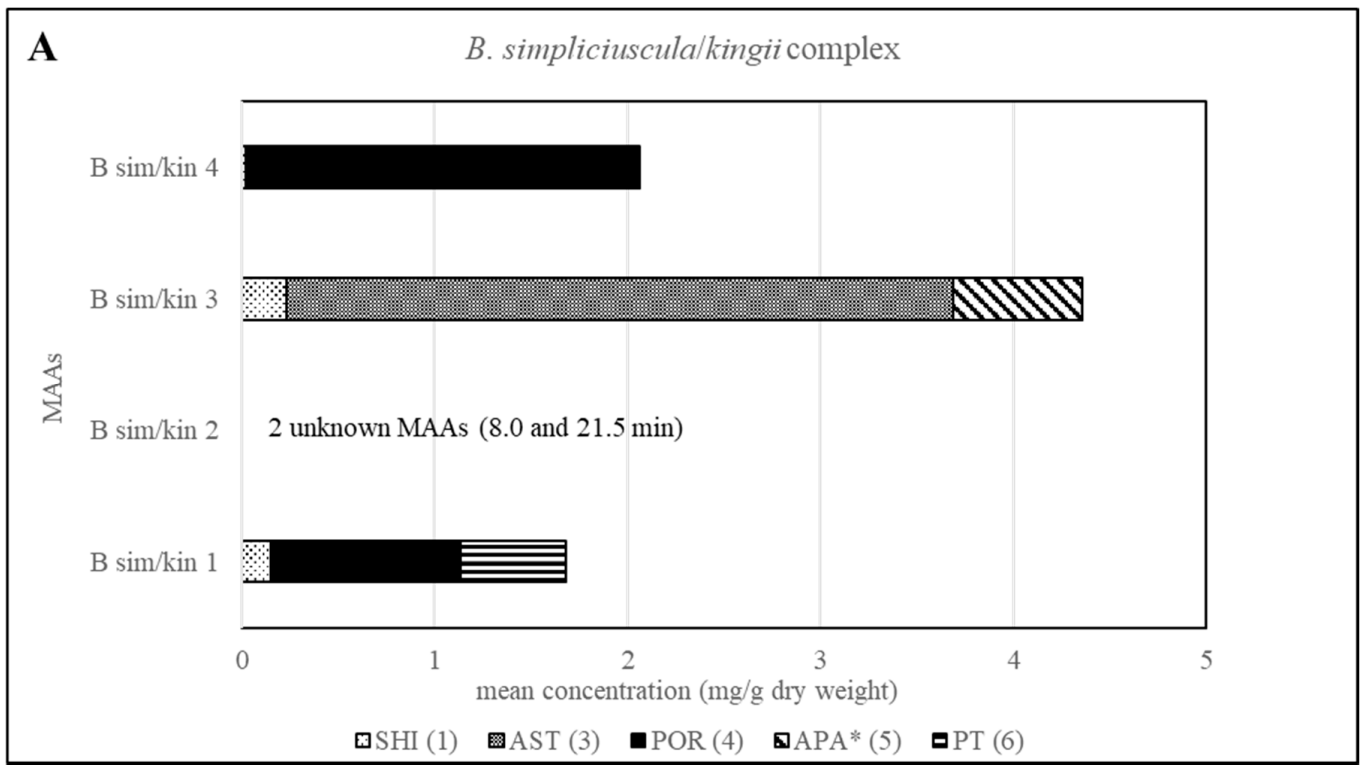

Figure 4. Overview of the content of MAAs expressed as mean value in mg per g of dry material for each lineage of the B. simpliciuscula/kingii complex. Assignment of the species: B sim, B. simpliciuscula; B kin, B. kingii.* Tentative assignment because palythinol shows identical mass, retention time and UV spectra.

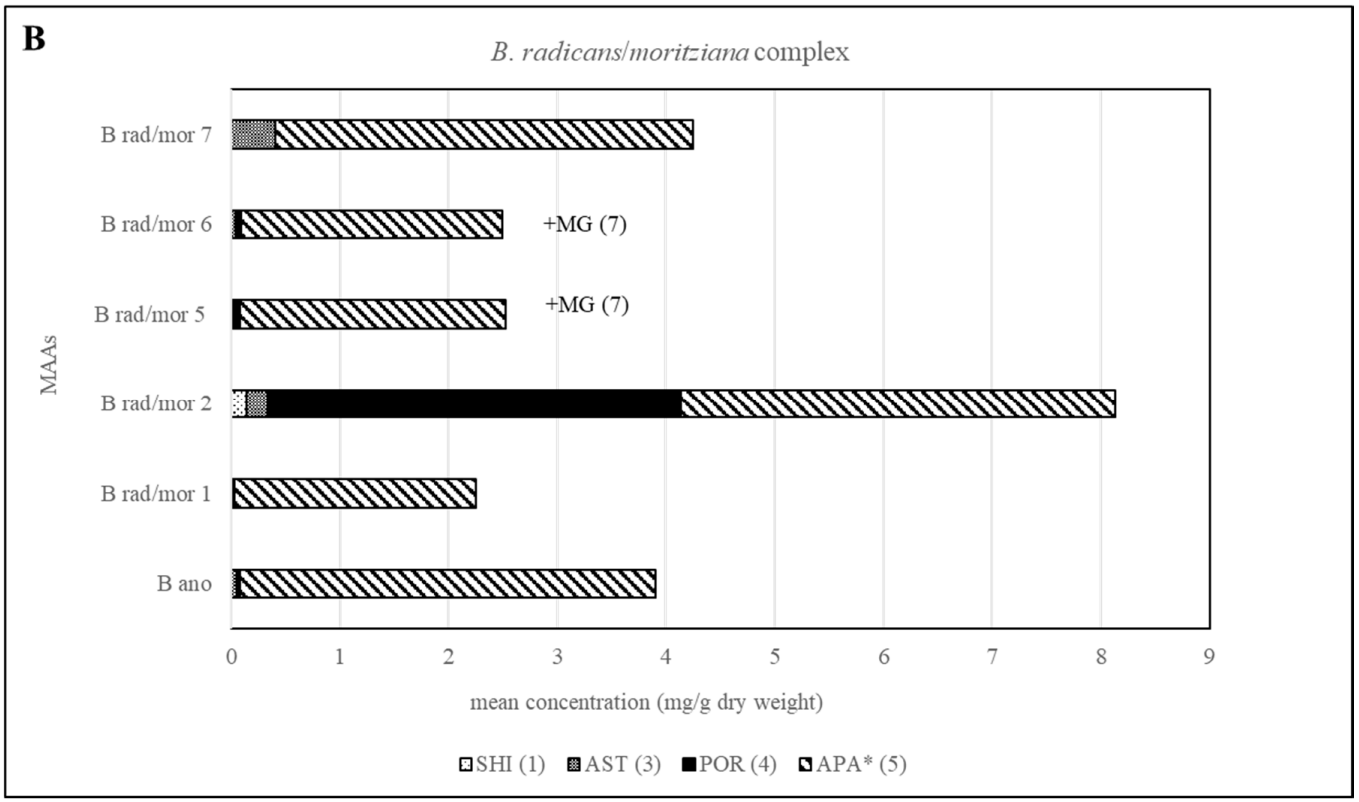

Figure 5. Overview of the content of MAAs expressed as mean value in mg per $g$ of dry material for each lineage of the B. moritziana/B. radicans complex. Assignment of the species: B rad, B. radicans; B mor, B. moritziana; B ano, B. anomala. * Tentative assignment because palythinol shows identical mass, retention time and UV spectra.

Furthermore, all other investigated Bostrychia spp. showed different MAA patterns, which in most cases were specific for each species (Figure 6 and Table S3), suggesting that MAAs can be considered as suitable biomarkers for this genus. Additionally, it was found that the generation, sex and developmental stage of the algae does not affect the production of MAAs since samples in different stages revealed identical MAA patterns. Besides, no consistent pattern was found in MAA quantity in relation to developmental stage or age of samples. 


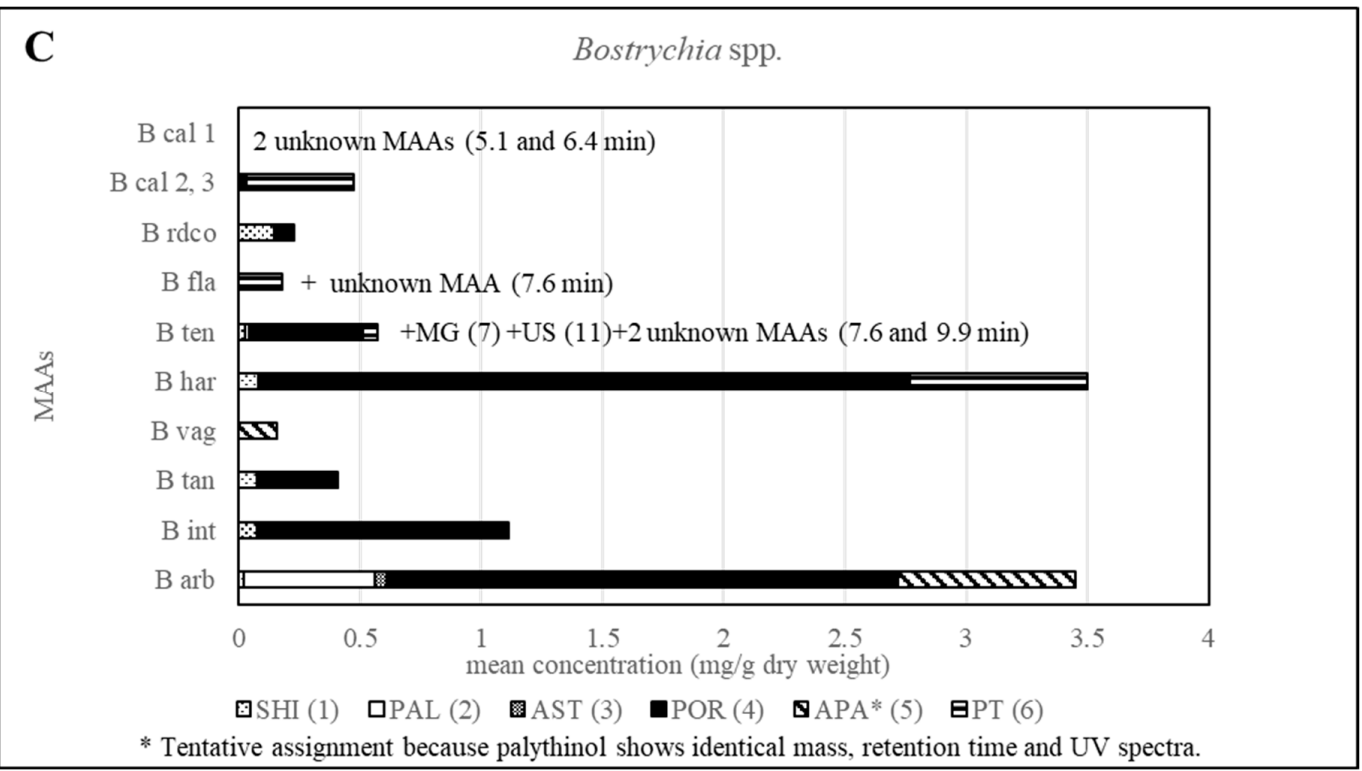

Figure 6. Overview of the content of MAAs expressed as mean value in mg per $\mathrm{g}$ of dry material for various Bostrychia species. Assignment of the species: B arb, B. arbuscula; B int, B. intricata; B tan, B. tangatensis; B vag, B. vaga; B har, B. harveyi; B ten, B. tenella; B fla, B. flagellifera; B cal, B. calliptera; B rdco, B. radicosa.

Finally, for each isolate of B. tenella and B. flagellifera, samples from culture and herbarium (field samples) were available. Again, regardless its origin for most samples the MAA pattern was identical and only quantitative differences could be observed for very old (in some cases more than 30 years old) samples. This was the case for MAAs with cyclohexenimine scaffold, which are known to be stable in a wide range of conditions [14]. However, mycosporine-glycine which has a cyclohexenone scaffold and is reported to be instable, was only present in culture samples. The unknown MAA at 9.9 min was also present in some B. tenella samples from culture but not in herbaria specimens. Surprisingly, usujirene was found in both culture and herbaria samples although it is also reported to be instable [14].

Future research perspectives of this study include the examination of other algal species, known to include cryptic species with the developed analytical method, in an effort to identify chemotaxonomic markers for them, too as well as the analysis of uninvestigated species aiming for the discovery of novel MAAs. Structure elucidation of the unknown MAAs, found in this study would be a further task requiring much higher available biomass of the algal material. Furthermore, the examination the MAA content of specific species with the developed analytical method growing under diverse environmental conditions such as various levels of salinity, nutrients supply, temperature, $\mathrm{pH}$ or UV radiation could reveal if the MAA production is induced under specific conditions and clarify whether MAAs serve other purposes apart from their photoprotective role such as osmoprotection or cryoprotection. Finally, re-examination of the B. moritziana/B. radicans complex including all seven reported lineages with a focus on different metabolites such as phenolic compounds, terpenoids or carotenoids would provide a broader overview of the chemotaxonomy of this complex and could possibly reveal markers for lineages 5 and 6 which were indistinguishable according to their MAA production.

\section{Experimental}

\subsection{Biological Material}

All of the red algae investigated were collected and morphologically identified by two of the authors (John West and Mitsunobu Kamiya) as well as by Prof. G. C. Zuccarello (Victoria University of Wellington, New Zealand), using their taxonomic expertise in conjunction with DNA sequencing data. 
The sequencing data are reported in previous publications which are mentioned in Tables S1 and S2. Details regarding species, collection date and place are summarized in Table S3.

\subsection{Chemicals}

Methanol for analysis had at least pro analysis (p.a.) quality and was obtained from Merck (Darmstadt, Germany). Formic acid was purchased from VWR International (Vienna, Austria) and ammonium formate from Serva (Heidelberg, Germany). Ultrapure water was produced by a Sartorius arium ${ }^{\circledR} 611$ UV (Göttingen, Germany) purification system.

\subsection{Analyte Isolation}

All standard compounds were isolated as described in $[12,14]$. Original NMR-spectra are available from the authors upon request. The purity of the standard compounds was assured by NMR, HPLC-DAD and HPLC-MS and was determined to be above 95\%.

\subsection{HPLC Sample Preparation for Quantitation Purposes}

For the preparation of each sample, $2-40 \mathrm{mg}$ plant material of Bostrychia spp. was frozen in liquid nitrogen and homogenized with a micropestle. This homogenization procedure was done separately for each sample used in the different experiments (quantitation purpose, assay precision, assay accuracy). For extraction, $4.0 \mathrm{~mL}$ of pure water was added to the algal material, mixed with a Vortex mixer (VWR) and subsequently extracted by sonication (15 $\mathrm{min}$ at ambient temperature). After centrifugation at $2000 \times g$ for $5 \mathrm{~min}$ the supernatant was placed in a $25 \mathrm{~mL}$ volumetric flask. This procedure was repeated two more times, and the flask filled up to the final volume with the extraction solvent. Afterwards, a specific volume of extract (30/divided by the mass of the dry plant material) was transferred to a vial, evaporated till dryness and redissolved in $1 \mathrm{~mL}$ of water $100 \%$. This step was necessary in order to adjust the concentration so that the samples were suitable for analysis. Finally, the redissolved extract was filtered through Phenex-RC $4 \mathrm{~mm}$ Syringe Filters $0.45 \mathrm{u}$ (Phenomenex, Torrance, CA, USA).

\subsection{General Experimental Procedures}

\subsubsection{HPLC-DAD Analysis}

HPLC analyses were performed on an Agilent 1100 series HPLC instrument, equipped with quaternary pump, autosampler, column oven, and a photodiode array detector (Agilent, Waldbronn, Germany). Optimum separation was achieved on a YMC-Pack ODS column $(250 \mathrm{~mm} \times 4.60 \mathrm{~mm}, 5 \mu \mathrm{m})$ from YMC, guarded with an in-line filter and using a mobile phase consisting of $20 \mathrm{mM}$ ammonium formate and $0.25 \%(v / v)$ formic acid in water (A) and methanol (B). The applied gradient was as follows: $100 \%$ A from 0 to $20 \mathrm{~min}, 80 \% \mathrm{~A}$ at $30 \mathrm{~min}, 2 \% \mathrm{~A}$ at $35 \mathrm{~min}$, and held at this composition for $5 \mathrm{~min}$ (total runtime of $40 \mathrm{~min}$ ); then the column was equilibrated for $15 \mathrm{~min}$ under the initial conditions. Flow rate, temperature, and injection volume were adjusted to $0.65 \mathrm{~mL} / \mathrm{min}, 7^{\circ} \mathrm{C}$, and $5.0 \mu \mathrm{L}$. Detection wavelengths were set to 310,330 and $350 \mathrm{~nm}$. Due to the high content of compound 4 in samples B mor $4591 \mathrm{~T}$ and B mor $4590 \mathrm{~V}$, the injection volume had to be reduced from $5 \mu \mathrm{L}$ to $3 \mu \mathrm{L}$.

\subsubsection{HPLC-DAD-MS Analysis}

Liquid chromatography-diode array detector-electrospray ionization-mass spectrometry (LC-DAD-ESI-MS) experiments were performed on an Agilent 1260 HPLC system (Santa Clara, CA, USA), which was coupled to an amaZon iontrap mass spectrometer (Bruker, Bremen, Germany). HPLC separation conditions were identical with those described above. MS-spectra were recorded in alternating-ESI mode (capillary voltage $4.5 \mathrm{kV}$ ), with a drying gas temperature of $200^{\circ} \mathrm{C}$, the nebulizer gas (nitrogen) set to $4.4 \mathrm{psi}$, and a nebulizer flow (nitrogen) of $6 \mathrm{~L} / \mathrm{min}$. The scanned mass range was set between $\mathrm{m} / \mathrm{z} 100$ and 1200 . 


\subsection{Calibration and Method Validation}

The HPLC method used was adapted from a previously published one [11] and validated according to ICH guidelines [15] in order to ensure that it fulfilled regulatory standards. All validation results are summarized in Table 1.

\subsubsection{Linearity, Limit of Detection (LOD) and Limit of Quantification (LOQ)}

Standard stock solutions were prepared by separately weighting and dissolving compounds 1, 4, 5, 8 and 10 in water 100\%. From each stock solution, at least eight calibrator levels were prepared by dilution with pure water, and each level was assayed in triplicate (see Table 1 for calibration data). Calibration curves were prepared by plotting the peak areas versus the concentrations of each analyte. The regression parameters (intercept, slope, and determination coefficient) were calculated by linear regression analysis, using Microsoft Excel. The LOD and LOQ for each analyte were calculated from the regression models, including only the lowest four dilution levels. The LOD was calculated as 3.3 times the residual standard deviation of the regression line divided by the slope of the calibration curve, whereas the LOQ was calculated as 10 time the residual standard deviation divided by the slope.

\subsubsection{Precision and Accuracy}

Precision was assured by analysing three individually homogenized and prepared extracts of a B. arbuscula sample (B arb) on three consecutive days in triplicate. Intra and interday assay precision was expressed as the relative standard deviation (RSD) of the replicate quantitative measurement of compounds 1-5. Accuracy was determined by recovery experiments at three different concentration levels (low, medium, high). For this purpose, individually homogenized B. arbuscula samples (B arb) were spiked with known amounts of analytes 1, 4, 5, 8 and 10 prior to sample workup. All samples were prepared in triplicate.

Supplementary Materials: The following are available online. UV and mass spectra of the unidentified MAAs, collection sites and dates of the investigated samples of Bostrychia spp. and detailed quantitative HPLC-DAD results for compounds 1-12 in each Bostrychia spp.

Author Contributions: M.O. did all practical work and prepared the first draft of the manuscript; J.W. and M.K. supplied and identified the algae, A.H. and M.G. supervised M.O., helped with all methodological approaches, and finalized the paper along with the other co-authors. All authors have read and agreed to the published version of the manuscript.

Funding: This research was funded by the Austrian Science Fund (FWF), project No. P29671.

Acknowledgments: The authors gratefully thank Joe Zuccarello (School of Biological Sciences, Victoria University of Wellington, New Zealand) for collection and identification of part of the plant material.

Conflicts of Interest: The authors declare no conflict of interest.

\section{References}

1. Saengkaew, J.; Muangmai, N.; Zuccarello, G. Cryptic diversity of the mangrove-associated alga Bostrychia (Rhodomelaceae, Rhodophyta) from Thailand. Bot. Mar. 2016, 59, 363-371. [CrossRef]

2. Guiry, M.D.; Guiry, G.M. AlgaeBase; World-Wide Electronic Publication, National University of Ireland: Galway, Ireland, 2019. Available online: http://www.algaebase.org (accessed on 11 July 2019).

3. King, R.; Puttock, C. Morphological and taxonomy of Bostrychia and Stictosiphonia (Rhodomelaceae/ Rhodophyta). Aust. Syst. Bot. 1989, 2, 1-73. [CrossRef]

4. Khin Gyi, K.; Htun, U.S. The genus Bostrychia Montagne (Ceramiales, Rhodophyta) in Setse and Kyaikkhami coastal areas. Mawlamyine Univ. Res. J. 2012, 4, 1-17.

5. Zuccarello, G.C.; West, J.A.; Kamiya, M. Non-monophyly of Bostrychia simpliciuscula (Ceramiales, Rhodophyta): Multiple species with very similar morphologies, a revised taxonomy of cryptic species: Polyphyletic Bostrychia species. Phycol. Res. 2018, 66, 100-107. [CrossRef]

6. Zuccarello, G.; West, J.; Goer, S. Diversity of the Bostrychia radicans/Bostrychia moritziana species complex (Rhodomelaceae, Rhodophyta) in the mangroves of New Caledonia. Cryptogam. Algol. 2006, 27, 245-254. 
7. Zuccarello, G.; West, J.; King, R. Evolutionary divergence in the Bostrychia moritziana/B. radicans complex (Rhodomelaceae, Rhodophyta): Molecular and hybridization data. Phycologia 1999, 38, 234-244. [CrossRef]

8. West, J.; Kamiya, M.; Goer, S.; Karsten, U.; Zuccarello, G. Observations on some mangrove-associated algae from the western Pacific (Guam, Chuuk, Kosrae, and Pohnpei). Algae 2013, 28, 241-266. [CrossRef]

9. West, J.; Goer, S.; Zuccarello, G. Monosiphonous growth and cell-death in an unusual Bostrychia (Rhodomelaceae, Rhodophyta): B. anomala sp. nov. Algae 2013, 28, 161-171. [CrossRef]

10. Carreto, J.; Carignan, M.; Montoya, N. A high-resolution reverse-phase liquid chromatography method for the analysis of mycosporine-like amino acids (MAAs) in marine organisms. Mar. Biol. 2005, 146, 237-252. [CrossRef]

11. Hartmann, A.; Becker, K.; Karsten, U.; Remias, D.; Ganzera, M. Analysis of Mycosporine-Like Amino Acids in Selected Algae and Cyanobacteria by Hydrophilic Interaction Liquid Chromatography and a Novel MAA from the Red Alga Catenella repens. Mar. Drugs 2015, 13, 6291-6305. [CrossRef] [PubMed]

12. Orfanoudaki, M.; Hartmann, A.; Karsten, U.; Ganzera, M. Chemical profiling of mycosporine-like amino acids in twenty-three red algal species. J. Phycol. 2019, 55, 393-403. [CrossRef] [PubMed]

13. Orfanoudaki, M.; Hartmann, A.; Ngoc, H.N.; Gelbrich, T.; West, J.; Karsten, U.; Ganzera, M. Mycosporine-like amino acids, brominated and sulphated phenols: Suitable chemotaxonomic markers for the reassessment of classification of Bostrychia calliptera (Ceramiales, Rhodophyta). Phytochemistry 2020, 174, 112344. [CrossRef] [PubMed]

14. Carreto, J.I.; Carignan, M.O. Mycosporine-like amino acids: Relevant secondary metabolites. Chemical and ecological aspects. Mar. Drugs 2011, 9, 387-446. [CrossRef] [PubMed]

15. ICH official Web Site: ICH. Available online: https://www.ich.org/ (accessed on 14 July 2020).

(C) 2020 by the authors. Licensee MDPI, Basel, Switzerland. This article is an open access article distributed under the terms and conditions of the Creative Commons Attribution (CC BY) license (http://creativecommons.org/licenses/by/4.0/). 